\title{
Effects of Technology and Sustainable Development on Japanese Translation Industry in Vietnam
}

\author{
Vo Hoang $\mathrm{Ca}^{1, *}$ Nguyen Tan Danh ${ }^{2}$ \\ ${ }^{1}$ Ho Chi Minh City Open University, Ho Chi Minh city, Vietnam \\ ${ }^{2}$ FPT University, Ho Chi Minh City, Vietnam
}

\begin{abstract}
As a large city with advantages in tourism infrastructure, Ho Chi Minh City is always considered the leading tourist centre of the country. The most important task of city tourism today is to improve quality and diversify products, making this industry one of the key economic sectors. Tourism potentials and advantages have not been effectively exploited to become a unique and attractive tourism product of Ho Chi Minh City. Some tourists seem to still only consider this as a stopover or transit point because there are large international and domestic routes before reaching other destinations in Vietnam. Ho Chi Minh City tourism is gradually losing this advantage when key tourist areas are completing international airports and convenient road transport infrastructure. In addition, Ho Chi Minh City tourism has also developed over the past time, but there are not many typical products. Therefore, before losing its advantages and its potential, Ho Chi Minh city should focus on building a unique and diversified tourism product system to attract tourists. This paper analyses the challenges that Ho Chi Minh City is facing and mention some recommendations. The results of the paper through the analysis process show that the tourism industry of Ho Chi Minh City has advantages and disadvantages that need to be overcome in order to build a more sustainable tourism brand.
\end{abstract}

\section{Introduction}

Today's translation technology is different from a few years ago. If in the past, the translation technology was only encapsulated in computer translation software with few features, and quite a lot of limitations, until now the translation technology is proving its position. it helps many people to communicate with each other in the easiest way. With only a smartphone with internet connection, we can basically communicate with foreigners (Google Translate). Recently, Microsoft and Samsung continue to show great things with the introduction. unique translation features, better user support. The voice recognition technology beats the team of translators, or the translation features unique to new Samsung phones. More complete speech recognition technology.

This is a major milestone and gives Microsoft a solid sound foundation to go from translating to understanding the meaning of what is being said. October 2016 marked a

\footnotetext{
*Corresponding author: ca.vh0121@oude.edu.vn
} 
milestone for artificial intelligence when Microsoft announced that its system can translate a phone call as equal or even better than a human.

The achievements of science and IT in developing and supporting people today are far beyond human imagination decades ago. For translation and translator in general, what are we getting? Considering some of the prominent technological innovations in translation recently introduced is a clear demonstration of how machines and technology help us humans.

\section{Research content}

\subsection{The concepts of technology and translation}

Technology is the invention, change, use, and knowledge of tools, machines, techniques, professional skills, systems, and organizational methods, in order to solve a problem, improve an existing solution, achieve a goal, or perform a specific function. Technology significantly affects the ability of humans and other animals to control and adapt to their natural environment. To put it simply, technology is the application of scientific inventions to real and specific goals or products that serve human life, especially in industrial or commercial fields. The term technology can be used in general or for specific disciplines, for example "construction technology", "information technology".

Translation, interpretation, or language conversion is an activity that involves interpreting the meaning of a passage in a language - the source text - and converting to another language into a new and equivalent paragraph - the translated text. While interpretation - oral translation - has facilitated oral or sign language communication between users of different languages, born before writing, translation began only after the literature had been recorded in developed scripts. Due to the need for translation of business documents that led to the beginning of the industrial revolution in the mid-18th century, a number of translation majors were standardized, with professional schools and professional associations.

In the translation field, automatic translation is considered as a familiar term. Automatic translation or also called as machine translation, is a branch of a natural language process of artificial intelligence sub-sector. It is a combination of language, translation and computer science. As the name implies, auto translation performs the translation of one language (called source language) into one or more other languages (called target language) automatically, without human intervention in the process. In other words, it can be understood as translating a text without any human intervention.

\subsection{Popularity of translation-related tools and equipment}

Fully computerized translation (MT) is a type of translation in which a computer fully undertakes the translation of a text from one language to another. The user, who is not necessarily a translator or knows the original language or/and the target language) just needs to load the original text into the machine and order the translation [1]. The working principle is that the programmers pre-load the words and the structure, the sample wording in the original language, and the target language into the software. The computer compares the input language with this database to give the optimal translation. This working principle is called as Dictionary based machine translation combined with Rule based machine translation. However, this working principle is no longer used much due to the lack of natural and inaccurate computer products [2]. 


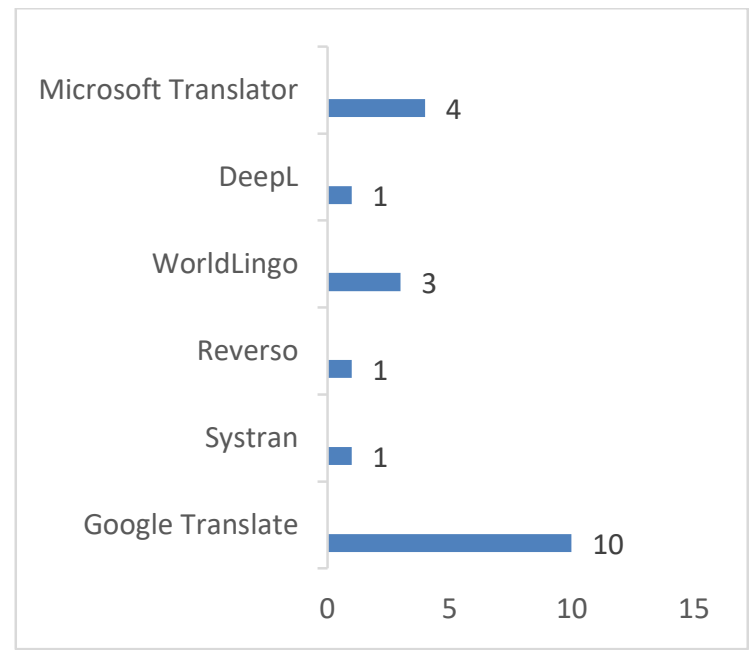

Fig. 1. Popularity of some automated translation tools.

In addition to automatic translation tools and software, we also have hardware devices to support direct translation in many cases without the need for an interpreter. Furthermore, a lot of translation software and equipment are also sold at the market with quite reasonable prices [3]. Even in some common contexts, translation devices have an advantage over humans. Therefore, even language teachers are likely to have a job competition in the era of industrial revolution 4.0 (Figure 1).

\subsection{Current situation of translation industry and development of translation- related technologies in Vietnam}

With today's rapidly developing globalized business environment and the fact that many people do not know another foreign language, especially English [1], the demand for translation services is on the rise. The modern language industry is rapidly growing with the introduction of the internet. Its achievements include the ability to quickly translate long documents into many other languages. This creates new challenges for traditional translation activities, such as quality assurance. There are a number of quality standards such as the European EN 15038 and the F2575-06 in the US.

There are so many small and large companies in the language industry, but so far there has been no one that dominates the world market. Human resources for translation are on many other different levels. Thanks to the connectivity of the Internet, from professional translators, students, language teachers, to professionals in other industries, all can participate in translation services [3].

According to current statistics, the translation market in Vietnam is only about 100 million USD / year, far behind the 14 billion USD / year globally. Most of them belong to foreign companies [1].

Over the past 10 years, the translation market around the world has grown very strongly. In Vietnam, economic integration and international cooperation have brought many open business opportunities for businesses [4]. The strong growth in the number of goods, publications, services and deals with foreign countries proves the explosion in translation in the country. Since then, the translation market in our country has become more and more bustling, then brought a common voice to domestic and international organizations as well as promoted the integration to a new level [2]. 
According to estimates, if our country's translation industry wants to rise and can be taken to be compared to other translation industry in the world, it must reach about 500 million USD / year. The negative thing is that most of the translation market is in the hands of foreign companies [5]. They re-hire human resources in Vietnam at a much cheaper price than the market price. But the translation price of foreign units compared to domestic companies is 30-40 times higher. It can be seen that the difference between Vietnamese companies and foreign enterprises is very large, but almost all customers prefer foreign companies [3]. The first reason is that foreign organizations always strictly follow international translation standards - which is quite unfamiliar to Vietnamese translation. In our country [5], adding or removing the meaning of a sentence compared to the original document is quite common. In addition, the use of specialized terminology in an inconsistent way, with no investment in expertise and limitation in the use of translation support software makes clients not trust in the domestic translation market [6].

\subsection{Statistical data}

The Covid-19 pandemic is happening all over the world including Vietnam and Japan. Japanese FDI enterprises also fell into a difficult situation. According to the 2014 investment report of the Japan External Trade Organization (JETRO), the US is still the largest investment partner of Japan with a total FDI investment in the US of 43.7 billion USD equal to a $36.7 \%$ increase. Besides, Japanese companies are diverting investment out of China and increasing investment in ASEAN countries [7]. This is due to the rising labour costs in China and the growing tensions between the two countries over maritime sovereignty [4]. The amount of Japanese FDI invested in China fell $32.5 \%$ to 9.1 billion USD. In contrast, ASEAN, with a market of 600 million people, has attracted a record high amount of FDI from Japan of 23.6 billion USD, an increase of 2.2 times compared to the previous year. With the increasing investment in ASEAN countries, including Vietnam, in addition to the gradual withdrawal of investment in other markets due to the Covid-19 pandemic, career opportunities for Vietnam's translation industry are expected to remain high for next years.

\subsection{Methodology}

This article uses the survey method on the online Google Form with the students majoring in Japanese language at FPT University with opinions related to the popularity of translation tools and evaluation on the level of accuracy in translating and interpreting objectively supported with supporting software, devices and the popularity of which automatic translation tools are widely used. On that basis, the opinions about the future of translation for the nowadays technological development are summarized.

\subsection{Research results and discussion}

Through surveys and researches, it is found that the advantages and shortcomings in using language tools. In the administrative documents in which there are clear and structured sentences, the accuracy of the translation is higher than the translation of the texts of linguistic flutter in poetics because the translation of such texts has many lexical errors. It can be seen that today's translation tools are very rich and varied. Until now, the most popularity has been Google Translate. Although it has achieved an amazing accuracy, Google Translate are not good at all types of texts [4].

Translation is not a new term as it has been around for 60 years. However, in the past several years, the Translation and Language Services industry really took notice of translation 
tools. The main reason for this change of perception is the introduction of AI - artificial intelligence and its optimization [7].

In order to meet the human communication needs, nowadays, automatic translation systems are being developed significantly in both quantity and quality. However, the quality of automatic translation is still quite low compared to expectations, especially under resourced languages such as Vietnamese and ethnic minority languages [8]. Even for languages that are popular and have a huge investment such as English, French, Chinese, Japanese, the quality of automatic translation between these languages still has problems that need improving [5]. To evaluate translation systems, first, we must prepare multilingual data written in many different languages such as English, French, Russian, etc. with the best possible quality. We will use these data for translation text and reference translation (for comparison with machine translation in the future) [2] (Figure 2).

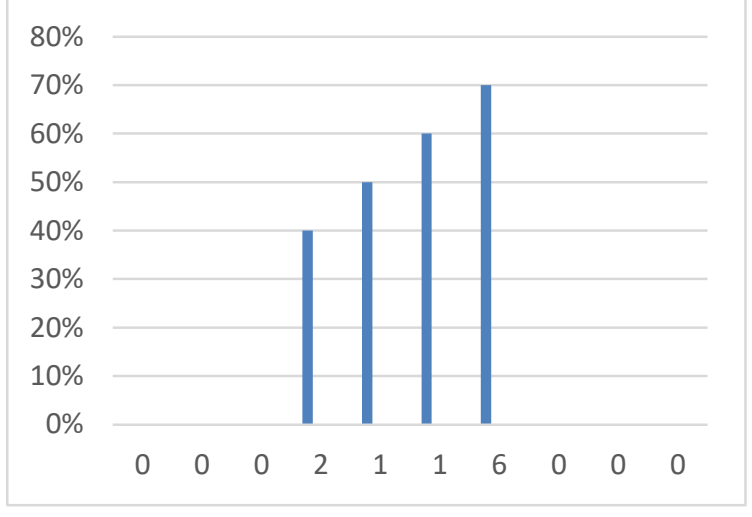

Fig. 2. Overall assessment of the automatic translation tools' accuracy

The following example is an original paragraph in the short story named Diary of a Cricket by To Hoai, a Vietnamese writer: "Chẳng bao lâu tôi đã trở thành một chàng dế thanh niên cường tráng. Đôi càng tôi mẫm bóng. Những cái vuốt ở chân, ở khoeo cứ cứng dần và nhọn hoắt." With Google Translate, the sentence is translated in English as "Soon I became a strong young cricketer. The more I melt the ball. The claws in the legs, the stools are stiff and sharp.”, and in Japanese as “「すぐに私は強い若いクリケッターになりました。それはボールを 溶かしました。私の足の爪は固くて鋭いものでした。」. The first sentence is translated with relatively precise semantics, although "strong young" or「強い若い」is not clear enough to describe the symbolism of the adjective "cường tráng" (mighty) in Vietnamese. For the second sentence "Đôi càng tôi mẫm bóng", the meaning of the translation is completely wrong as "The more I melt the ball." because the meaning of the translation is completely different from the meaning of the original sentence. In Japanese, the corresponding translation of it is “「それはボールを溶かしました」” which is not related to the original sentence as well. The above phenomenon is easily encountered when we use automatic translation tools, not only Google translate but also other tools available in the world, for the purpose of translating creative, non-compliant documents [6]. This gap, perhaps a potential opportunity, holds promise for the auto translation giants to develop and upgrade the system further, but the service improvement journey is still very difficult and demands the accumulation of data over the years.

One of the important reasons affecting the quality of automatic translation is the quality of the corpus used for translation systems. Evaluation campanges such as CSTAR, NESPOLE, and IWSLT have been well organized with many different subjective evaluations and objective evaluations. It is found that the quality of automatic translation for common 
language pairs is only acceptable in certain areas and the quality of translation is poor if the corpus source is weak in both quality and quantity [3].

\subsection{Suggestions}

With the current development of information technology, it is difficult to avoid a future where the machine will replace humans in translation work with a cheaper cost than hiring a translator-interpreter. If the database of a certain automatic translation engine is collected to have a sufficiently large extent about the data of all languages in the world (e.g., Google Translate) and it not only can translate the pure grammatical or lexical meaning of a sentence, but it can also distinguish the whole context in a sentence, then the number of translators will be reduced significantly. However, there must be the ones moderating the translation content by the automatic translation tools because even more or less there are still mistakes [6]. Language is always evolving and forming many new words over generations, so there is also a need for people with enough language knowledge to detect errors and update new words for the translation engine database. Therefore, the first thing is to improve the quality of the automatic translation tools so that they can better support the translators-interpreters on their job [9].

In general, fully computerized translation technology can work in some situations such as when the original and target languages have the same linguistic family and the expressions are relatively similar (for example, English and French, English and Swedish), when the original version does not use many rhetoric, metaphors, and / or when the translation does not require elaboration of the sentence [10]. In specific cases when translating from English to Vietnamese or vice versa, the translation of this technology can often be used only for reference (briefly understand the content) [2]. In order to be able to build a quality and complete automatic translation system, in addition to research and improvement of automatic translation methods, finding the way to build the database not only having quantity, the number of language pairs, but also good in quality [3].

\section{Conclusion}

Although the translation tool system still has many flaws, it cannot be denied that its use makes translators save more time for the translation. As a result of the expansion of borders, the translation industry has become increasingly necessary. The process of international integration in the trend of globalization is inevitable for the expansion and development of a country. People need to talk to partners in different countries, languages and cultures, but not every business has the resources to meet this need. Therefore, that using technology equipment is more and more common is understandable. However, the current machines simply transmit information from words and passages with rigid basic meanings without really emphasizing on emotions or expressive speech while that is an important part of communication. In the next 10 years, the ability to automatically translate and completely replace people possible. That means translators should gradually worry about their future risk of unemployment. However, it must be admitted that, although the improvement of machine translation technology will bring a great deal of benefits to society, we should not expect a perfect translation tool, accurate to $100 \%$. That even human cannot do it, simply because different languages are hidden under culture, customs, people, etc. Translation technology creates a new area that requires theoretical consideration and discussion in order to achieve a unique structure and internal cohesion, which will be an important step on the path of academic and professional consolidation and development. 


\section{Conflict of interests}

\section{None}

\section{References}

1. J. Lv, Journal of Computational and Theoretical Nanoscience, 13(12), 10375 (2016)

2. Y. Fujii, Asian EFL Journal, 23, 41 (2007)

3. M.C. Odacioglu, S. Kokturk, Procedia-Social and Behavioral Sciences, 197, 1085 (2015)

4. J. Archer, Perspectives: Studies in translatology, 10(2), 87 (2002)

5. S. Rudnicki, Sociological Research Online, 22(2), 35 (2017)

6. D. Barr, Computer Assisted Language Learning, 26(4), 295 (2013)

7. X. Yang, X. Guo, S. Yu, Computer Assisted Language Learning, 29(3), 477 (2016)

8. I.M. Mees, B. Dragsted, I.G. Hansen, A.L. Jakobsen, Target. International Journal of Translation Studies, 25(1), 140 (2013)

9. K. Littau, Translation Studies, 9(1), 82 (2016)

10. M. Yamada, Intercultural communication review, 9, 97 (2011) 